\title{
Sensitivity analysis of a coupled hydrodynamic-vegetation model using the effectively subsampled quadratures method (ESQM v5.2)
}

\author{
Tarandeep S. Kalra ${ }^{1}$, Alfredo Aretxabaleta ${ }^{2}$, Pranay Seshadri ${ }^{3}$, Neil K. Ganju ${ }^{2}$, and Alexis Beudin ${ }^{4}$ \\ ${ }^{1}$ Integrated Statistics, contracted to the US Geological Survey, Woods Hole, MA, USA \\ ${ }^{2}$ US Geological Survey, Woods Hole, MA, USA \\ ${ }^{3}$ University of Cambridge, Cambridge, UK \\ ${ }^{4}$ University of Bordeaux, Bordeaux, France \\ Correspondence to: Tarandeep S. Kalra (tkalra@usgs.gov)
}

Received: 7 May 2017 - Discussion started: 6 June 2017

Revised: 19 September 2017 - Accepted: 25 October 2017 - Published: 8 December 2017

\begin{abstract}
Coastal hydrodynamics can be greatly affected by the presence of submerged aquatic vegetation. The effect of vegetation has been incorporated into the Coupled Ocean-Atmosphere-Wave-Sediment Transport (COAWST) modeling system. The vegetation implementation includes the plant-induced three-dimensional drag, in-canopy waveinduced streaming, and the production of turbulent kinetic energy by the presence of vegetation. In this study, we evaluate the sensitivity of the flow and wave dynamics to vegetation parameters using Sobol' indices and a least squares polynomial approach referred to as the Effective Quadratures method. This method reduces the number of simulations needed for evaluating Sobol' indices and provides a robust, practical, and efficient approach for the parameter sensitivity analysis. The evaluation of Sobol' indices shows that kinetic energy, turbulent kinetic energy, and water level changes are affected by plant stem density, height, and, to a lesser degree, diameter. Wave dissipation is mostly dependent on the variation in plant stem density. Performing sensitivity analyses for the vegetation module in COAWST provides guidance to optimize efforts and reduce exploration of parameter space for future observational and modeling work.
\end{abstract}

\section{Introduction}

The presence of aquatic vegetation (e.g., mangroves, salt marshes, and seagrass meadows) provides several ecological benefits including nutrient cycling, habitat provision, and sediment stabilization (Costanza et al., 1997). Vegetation provides a habitat for many species of epiphytes, invertebrates, and larval and adult fish (Heck et al., 2003). Seagrass meadows reduce sediment resuspension, thereby stabilizing bottom sediment, increasing light penetration, and improving water clarity in a positive feedback loop (Carr et al., 2010). In addition, aquatic vegetation provides coastal protection by absorbing wave energy (Wamsley et al., 2010).

One approach to implement the influence of aquatic vegetation on circulation is by increasing the bottom roughness coefficient (Ree, 1949; Morin et al., 2000). Recent studies involving 2-D depth-averaged models (Chen et al., 2007; Le Bouteiller and Venditti, 2015) have quantified the effect of vegetation through parameterization as "form drag" as opposed to "skin friction". To account for 3-D vertical structures, estuary-scale models have implemented both mean and turbulent flow impacts of vegetation (Temmerman et al., 2005; Kombiadou et al., 2014; Lapetina and Sheng, 2014). In addition to impacts on the flow field, the presence of vegetation also results in wave attenuation. The decay of wave height over vegetation has been simulated by enhancing bed roughness (Möller et al., 1999; de Vriend, 2006; Chen et al., 2007). A more physical description of wave attenuation due to vegetation was developed by Dalrymple et. al (1984), who approximated wave energy loss due to stalks approximated as cylinders. This approach has been applied in spec- 
tral wave models and calibrated against flume experiment results (Mendez and Losada, 2004; Suzuki et al., 2012; Wu, 2014; Bacchi et al., 2014).

Recently, Beudin et al. (2017) implemented the effects of vegetation in a vertically varying water column through momentum extraction and turbulence dissipation and generation using a 3-D hydrodynamic model and accounting for wave dissipation due to vegetation in a spectral wave model. The modeling approach was implemented and tested within the open-source COAWST (Coupled Ocean-AtmosphereWave-Sediment Transport) modeling system that couples hydrodynamic and wave models (Warner et al., 2010). The vegetation module was based on modifications to the flow field resulting from three-dimensional drag, in-canopy waveinduced streaming, and production of turbulent kinetic energy in the hydrodynamics model (Regional Ocean Modeling System - ROMS), along with energy dissipation and resultant hydrodynamic feedback from the wave model (Simulating WAves Nearshore - SWAN).

The vegetation module requires the user to input a given set of plant properties (stem density, height, diameter, and thickness). These vegetation properties can be highly variable depending on the season and environment, yet obtaining a full set of measurements in realistic settings is impractical. Identifying which properties have the greatest influence on the resulting flow dynamics can reduce the amount of observational data required to robustly parameterize the model and/or reduce the number of runs required in a model ensemble to quantify the uncertainty associated with data gaps. Our study aims to perform a systematic sensitivity analysis to quantify the effect of changing the vegetation properties on the resulting hydrodynamic output. The results of the sensitivity analysis can be used to select and rank the most important parameters for calibration. Two conditions are required for the model to display a significant sensitivity: (1) a sufficient modification of one of the forcing parameters and (2) a change in the leading terms of the dynamic equations of the model. While modifying the forcing parameters by a sufficient amount is required, the modification should remain within the natural range of variability of the parameters.

Several mathematical techniques have been utilized to perform sensitivity analysis. Bryan (1987) applied scaling analysis to an idealized domain and forcing, and found that closure parameters such as vertical diffusivity and wind stress curl were important controlling factors in thermohaline circulation. Bastidas et al. (1999) used multicriteria methods to find the sensitivity of land surface scheme models that couple biosphere-atmosphere interactions. The input variables (such as precipitation, air temperature and humidity, etc.) predict the evolution of soil skin temperature, soil moisture, etc. The input parameters obtained from the sensitivity analysis of the model showed consistency with physical properties for two different field sites and helped to identify insensitive parameters that led to an improvement in model description. Fennel et al. (2001) incorporated adjoint methods to perform sensitivity studies to refine ecological model parameters such that the underlining model can be applied to a wider range of conditions. Mourre et al. (2008) performed multiple simulations based on realistic variation of a forcing field to calculate the influence of model parameters on sea surface salinity. The metric used to measure the sensitivity was based on rms difference between the reference and modified model parameter. The results showed that lateral salt diffusivity had the strongest impact on surface salinity model response. Rosero et al. (2010) investigated the sensitivity of three different versions of a land satellite model (Noah LSM) applied to nine different sites based on different conditions (soil, vegetation, and climate). They utilized the Monte Carlo method to generate the first-order Sobol' indices (Sobol', 1993) to estimate the model sensitivity. The results showed that the optimal parameter values varied between different versions of the models and for different sites along with quantifying the nature of interactions between parameters. One of the challenges associated with a Monte Carlo approach to computing the Sobol' indices is the large number of model evaluations required for approximating conditional variance.

All these studies highlight various approaches to perform sensitivity analysis. Saltelli et al. (2008) provided a comparison of different sensitivity analysis methodologies and the optimal setup for specific combinations of parameters and model. Ultimately, the choice of sensitivity analysis methodology depends on multiple factors such as the computational cost of running the model, the characteristics of the model (e.g., nonlinearity), the number of input parameters, and/or the potential interactions between parameters. Saltelli et al. (2008) described variance-based techniques as providing the most complete and general pattern of sensitivity for models with a limited number of parameters, such as the vegetation module in COAWST. Sobol' indices, as a form of variance-based sensitivity analysis, provide a decomposition of the variance of a model into fractions that can be assigned to inputs or combinations of inputs. However, techniques involving the estimation of Sobol' indices (such as Monte Carlo methods) are expensive.

To reduce the computational cost and have desirable accuracy, techniques that involve approximating the global response of the model with a polynomial and then using its coefficients to estimate the Sobol' indices can be utilized ( $\mathrm{Su}$ dret, 2008). In this paper, we use a set of least squares polynomial tools based on subsampling to estimate our global polynomial response (Seshadri et al., 2017). Then, the coefficients of the polynomial are used to compute the Sobol' indices. These tools are implemented in the open-source package Effective Quadratures (EQ) method (Seshadri and Parks, 2017), and our current work provides one of the first applications of this methodology to quantify sensitivity of input parameters in coastal models. Therefore, the goal of the present work is to take advantage of the EQ method to provide Sobol' indices that quantify the sensitivity of the flow and wave dynamics to vegetation parameters in COAWST model. The 


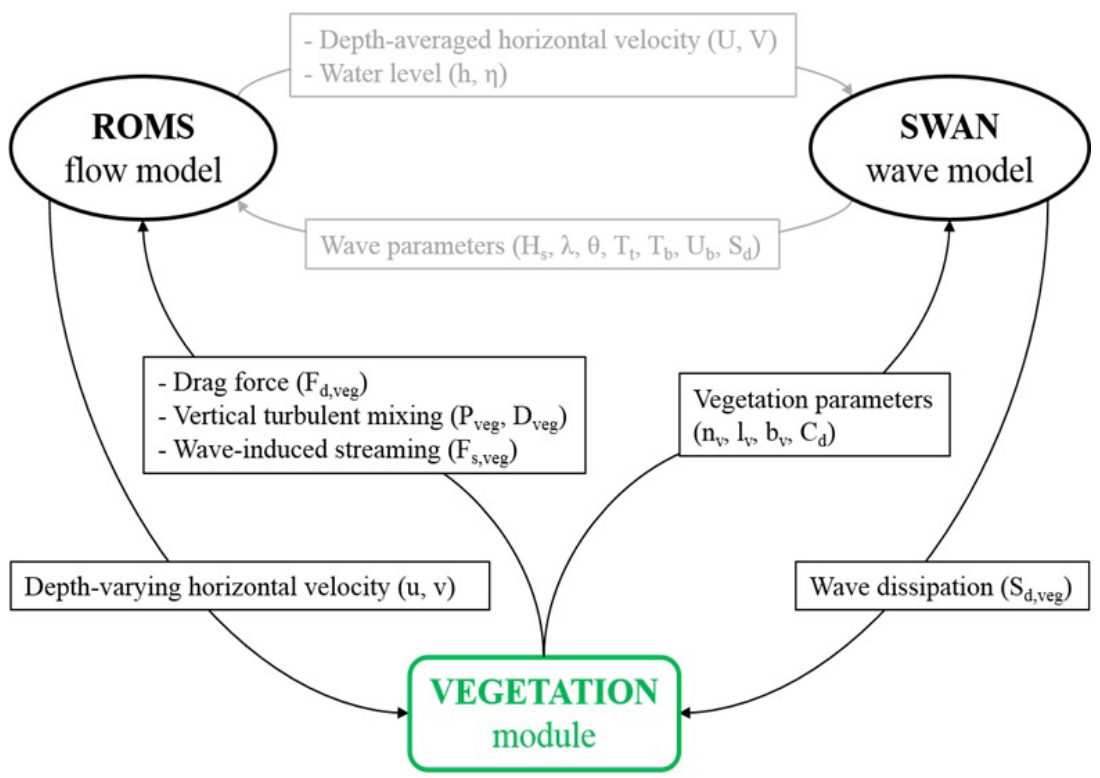

Figure 1. Schematic showing the vegetation module implementation in the COAWST model (figure adapted from Beudin et. al, 2017).

paper is organized as follows: the methods are discussed in Sect. 2, including the numerical model with vegetation model (COAWST), the Effective Quadratures method to estimate Sobol' indices, and simulation design; in Sect. 3, we present the results of sensitivity analysis from various simulations; in Sect. 4, we discuss the impact of these results; and finally, in Sect. 5, we summarize our work and outline areas of future research.

\section{Methods}

\subsection{COAWST implementation of vegetation model parameterization}

Beudin et al. (2017) implemented a hydrodynamicvegetation routine within the open-source COAWST numerical modeling system. The COAWST framework utilizes ROMS for hydrodynamics and SWAN for modeling waves coupled via the Model Coupling Toolkit (MCT) (Warner et al., 2008b).

ROMS is a three-dimensional, free surface, finitedifference, terrain-following model that solves the Reynoldsaveraged Navier-Stokes equations using the hydrostatic and Boussinesq assumptions (Haidvogel et al., 2008). The transport of turbulent kinetic energy and generic length scale are computed with a generic length scale (GLS) two-equation turbulence model. SWAN is a third-generation spectral wave model based on the action balance equation (Booij et al., 1999). The effect of submerged aquatic vegetation in ROMS is to extract momentum, add wave-induced streaming, and generate turbulence dissipation. Similarly, the wave dissipation due to vegetation modifies the source term of the ac- tion balance equation in SWAN. Sub-grid-scale parameterizations account for changes due to vegetation in the water column extending from the bottom layer to the height of the vegetation in the flow model, while SWAN accounts for wave dissipation due to vegetation at the seafloor. The parameterization of SWAN to account for wave dissipation implemented by Suzuki et al. 2012 has the same effect as energy dissipation.

The parameterizations used to implement the effect of vegetation in both ROMS and SWAN models are mentioned in Table 1 and detailed in Beudin et al. (2017). The coupling between the two models occurs with an exchange of water level and depth-averaged velocities from ROMS to SWAN and wave fields from SWAN to ROMS after a fixed number of time steps (Fig. 1). The vegetation properties are separately input in the two models at the beginning of the simulations.

\subsection{Method for sensitivity analysis: polynomial least squares}

Polynomial techniques are ubiquitous in the field of uncertainty quantification and model approximation. They estimate the response of some quantity of interest with respect to various input parameters using a global polynomial. From the coefficients of the polynomial, the mean, variance, skewness, and higher-order statistical moments can be calculated (see Smith, 2014; Geraci et al., 2016). In this paper, our interest lies in statistical sensitivity metrics called first-order Sobol' indices (Sobol', 1993) that are derived from the conditional variances of the parameters of the model. These indices are the same in number as the input parameters to the model and quantitatively rank the input parameters based on 
Table 1. Processes in ROMS and SWAN to model the presence of vegetation. The different input parameters (stem density, $n_{v}$; height, $l_{v}$; diameter, $b_{v}$; and thickness, $t_{v}$ ) affecting model wave and hydrodynamics are included.

\begin{tabular}{|c|c|c|c|c|c|}
\hline Process & Equation & $n_{v}$ & $l_{v}$ & $b_{v}$ & $t_{v}$ \\
\hline Extraction of momentum & $\begin{array}{l}F_{d, \text { veg, } u}=\frac{1}{2} C_{\mathrm{D}} b_{v} n_{v} u \sqrt{u^{2}+v^{2}} \\
C_{\mathrm{D}}=\text { Plant drag coefficient } \\
u, v=\text { Horizontal velocity components at each vertical } \\
\text { level }\end{array}$ & $\mathrm{X}$ & & $X$ & \\
\hline $\begin{array}{l}\text { Turbulence production } \\
\text { (Uittenbogaard, 2003) }\end{array}$ & $P_{\mathrm{veg}}=\sqrt{\left(F_{d, \mathrm{veg}, u} u\right)^{2}+\left(F_{d, \mathrm{veg}, v} v\right)^{2}}$ & $\mathrm{X}$ & & $\mathrm{X}$ & \\
\hline $\begin{array}{l}\text { Turbulence dissipation } \\
\text { (Uittenbogaard, 2003) }\end{array}$ & $\begin{array}{l}D_{\mathrm{veg}}=c_{2} \frac{P_{\mathrm{veg}}}{\tau_{\mathrm{eff}}} \\
\tau_{\mathrm{eff}}=\min \left(\tau_{\mathrm{free}}, \tau_{\mathrm{veg}}\right) \\
\tau_{\mathrm{free}}=\frac{k}{\varepsilon} \\
\tau_{\mathrm{veg}}=\left(\frac{L^{2}}{c_{k}^{2} P_{\mathrm{veg}}}\right)^{\frac{1}{3}} \\
L(z)=c_{l}\left(\frac{1-b_{v} t_{v} n_{v}}{n_{v}}\right)^{\frac{1}{2}} \\
P_{\mathrm{veg}}=\text { Turbulence production } \\
\tau_{\text {free }}=\text { Dissipation timescale of free turbulence } \\
k=\text { Turbulent kinetic energy } \\
\varepsilon=\text { Turbulence dissipation } \\
\tau_{\mathrm{veg}}=\text { Dissipation timescale of free turbulence } \\
c_{k}=\left(c_{\mu}^{0}\right)^{4} \simeq 0.09 \\
L=\text { Typical length scale between the plants } \\
c_{1}=\text { Lift coefficient of order unity }\end{array}$ & $\mathrm{X}$ & & $\mathrm{X}$ & $\mathrm{X}$ \\
\hline $\begin{array}{l}\text { Wave dissipation } \\
\text { (Mendez and Losada, } \\
\text { 2004) } \\
\text { (Dalrymple et al., } 1984 \text { ) }\end{array}$ & $\begin{array}{l}S_{d, v e g}=\sqrt{\frac{2}{\pi}} g^{2} \widetilde{C_{\mathrm{D}}} b_{v} n_{v}\left(\frac{\widetilde{k}}{\sigma}\right)^{3} \\
\frac{\sinh ^{3}\left(\widetilde{k} l_{v}\right)+3 \sinh \left(\widetilde{k} l_{v}\right)}{3 \widetilde{k} \cosh ^{3}(\widetilde{k} h)} \sqrt{E_{\mathrm{tot}}} E(\sigma, \theta) \\
\widetilde{C_{\mathrm{D}}}=\text { Bulk drag coefficient } \\
\widetilde{k}=\text { Mean wave number } \\
\widetilde{\sigma}=\text { Mean wave frequency } \\
h=\text { Water depth } \\
E_{\text {tot }}=\text { Total wave energy } \\
E=\text { Wave energy at frequency } \sigma \text { and direction } \theta\end{array}$ & $\mathrm{X}$ & $X$ & $\mathrm{X}$ & \\
\hline $\begin{array}{l}\text { Wave-induced streaming } \\
\text { (Luhar et al., 2010) }\end{array}$ & $\begin{array}{l}F_{S, \text { veg }}=\frac{S_{d, \text { veg,tot }} \widetilde{k}}{\rho_{0} \widetilde{\sigma}} \\
S_{d, \text { veg,tot }}=\text { Total wave energy dissipation } \\
\hat{k}=\text { Mean wave number } \\
\widetilde{\sigma}=\text { Mean wave frequency } \\
\rho_{0}=\text { Reference density of seawater }\end{array}$ & $\mathrm{X}$ & $X$ & $\mathrm{X}$ & \\
\hline
\end{tabular}

their contribution to the resultant model output. Thus, model output is more sensitive to parameters that exhibit higher first-order Sobol' index value. Second-order and third-order Sobol' indices may also be computed. The sum of the firstorder, second-order, and third-order Sobol' indices should be equal to unity; therefore, if the first-order indices are themselves close to unity, it indicates the higher-order interaction between model input parameters is weak.

In this paper, the first-order indices are computed from a global polynomial model using the effectively subsam- pled quadratures method (ESQM v5.2; Seshadri and Parks, 2017). There are two attributes to any data-driven polynomial model: the choice of the polynomial basis and the strategy for estimating the coefficients of the polynomial. The basis used in Effective Quadratures is orthogonal polynomials, i.e., orthogonal with respect to the weight of the input parameter. For example, if one of the input parameters is prescribed with a Gaussian distribution, then a Hermite orthogonal polynomial basis would be used; likewise, for a uniform distribution, Legendre polynomials are used. In the current 
(a)
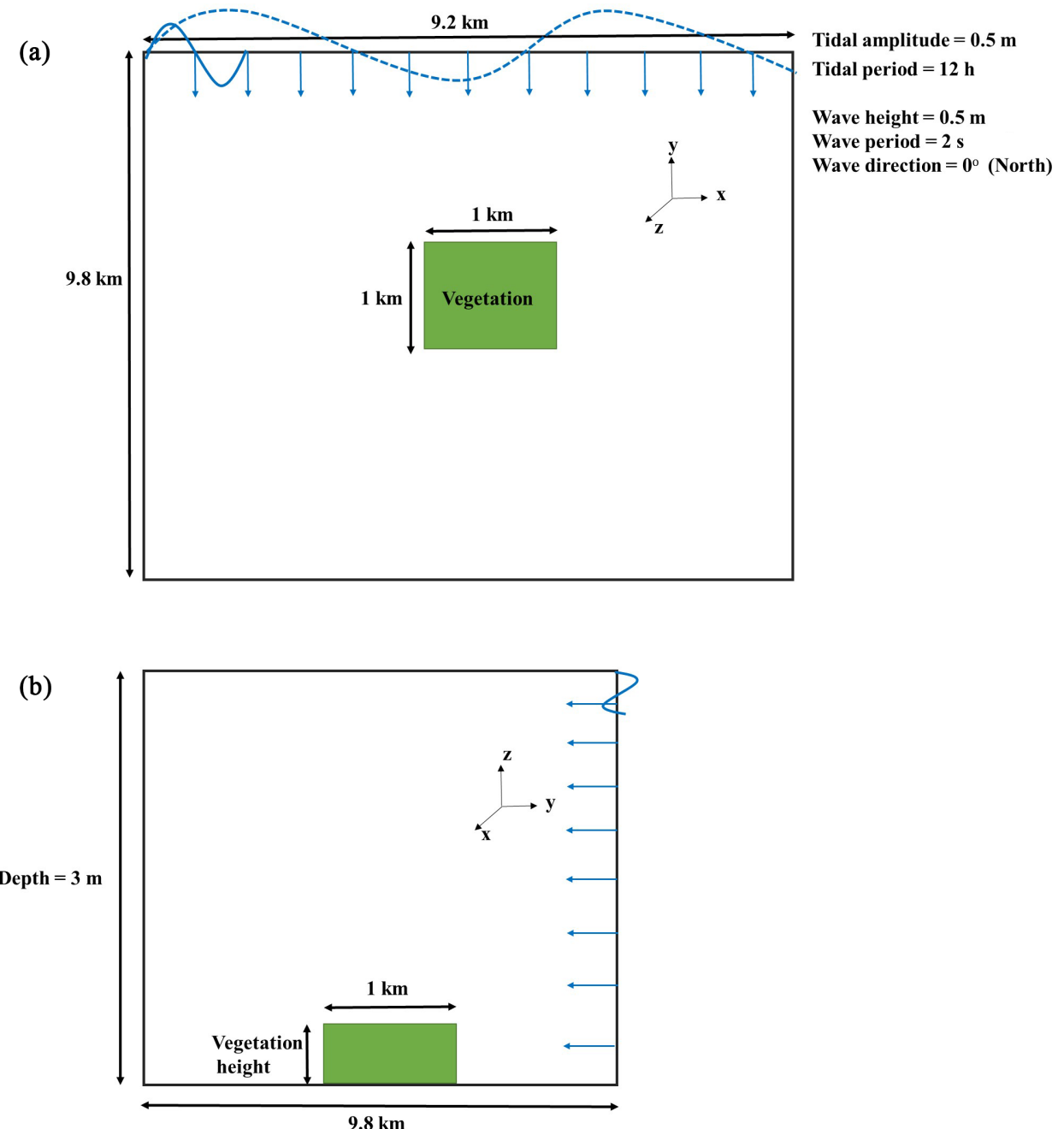

Figure 2. Schematic showing the idealized domain (not drawn to scale): (a) plan view and (b) cross-sectional view.

work, a uniform distribution is assumed for the input parameter space. The rationale behind selecting polynomials that are orthogonal with respect to the input weight is that it reduces the number of model evaluations required for estimating statistical moments. Details on the exponential convergence in moments when matching the orthogonal polynomial with its corresponding weight can be found in Xiu and Karniadakis (2002).

The coefficients for the polynomial expansion are typically approximated using an integral over the input parameter space using quadrature rules. When the number of input parameters is greater than one, tensor-grid or sparse-grid-based quadrature rules may be used to approximate these integrals. However, the cost of tensor grids grows exponentially with dimension; i.e., a four-point quadrature rule in three dimensions has $5^{3}$ points, in four dimensions has $5^{4}$ points, and so on. While some alleviation can be obtained using sparse grids, in this paper, a more efficient sampling technique is used: the effectively subsampled quadratures method (abbreviated to Effective Quadratures).

The method of Effective Quadratures determines points for approximating the integral by subsampling well-chosen points from a tensor grid and evaluating the model at those subsamples. These well-chosen points are obtained via a $\mathrm{QR}$ column pivoting heuristic (Seshadri et al., 2017). Once the coefficients are estimated, the Sobol' indices can be readily computed (Sudret, 2008).

\subsection{Range of input vegetation properties for sensitivity analysis}

Prior to performing the simulations for estimating Sobol' indices described above, a range of vegetation inputs that would impact the model response needs to be chosen. Kennish et al. (2013) constrained annual variation of three of the four vegetation properties (stem density, height, diameter) based on Zostera marina growth in the Barnegat Bay-Little 
Egg Harbor estuary. The thickness of Z. marina is selected to be an order of magnitude lesser than its diameter based on Larkum et al. (2007). Based on this, the range of the vegetation model inputs evaluated is as follows:

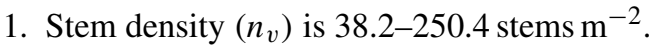

2. Height $\left(l_{v}\right)$ is $0.16-0.32 \mathrm{~m}$.

3. Diameter $\left(b_{v}\right)$ is $1.0-10.0 \mathrm{~mm}$.

4. Thickness $\left(t_{v}\right)$ is $0.1-1.0 \mathrm{~mm}$.

For the sensitivity analysis, a combination of these ranges of inputs (Table 2) is chosen to configure different simulations in an idealized test case (described below). In addition to these four vegetation properties, the vegetative model requires an input of drag coefficient $\left(C_{\mathrm{D}}\right)$ in the flow model and the wave model. However, variations on $C_{\mathrm{D}}$ are unlikely to be measured in the field, and thus users could rely on the published literature for an appropriate choice based on the type, shape, and flexibility of the vegetation under study.

\subsection{Test case configuration}

An idealized rectangular model domain of $10 \mathrm{~km}$ by $10 \mathrm{~km}$ with a $3 \mathrm{~m}$ deep basin is chosen. The grid is 100 by 100 in the horizontal ( $100 \mathrm{~m}$ resolution) and has 60 vertical sigmalayers (uniformly distributed) leading to $0.05 \mathrm{~m}$ resolution in the vertical. The vertical resolution of $0.05 \mathrm{~m}$ allows a plant height of $0.27 \mathrm{~m}$ to be distributed over six vertical layers while the shortest height is restricted to two vertical layers. A square patch of vegetation $(1 \mathrm{~km}$ by $1 \mathrm{~km})$ is placed in the middle of the domain (Fig. 2). The ROMS barotropic and baroclinic time steps are, respectively, 0.05 and $1 \mathrm{~s}$, while the SWAN time step and the coupling interval between ROMS and SWAN are $10 \mathrm{~min}$. The friction exerted on the flow by the bed is calculated using the Sherwood-Signell-Warner bottom boundary layer (SSW-BBL) formulation (Warner et al., 2008a). The bottom boundary layer roughness is increased by the presence of waves that produce enhanced drag on the mean flow (Madsen, 1994; Ganju and Sherwood, 2010). The vegetative drag coefficients $\left(C_{\mathrm{D}}\right)$ in the flow model and the wave model are set to 1 (typical value for a cylinder at high Reynolds number). The bed roughness is set to $0.05 \mathrm{~mm}$, which corresponds to a mixture of silt and sand (Soulsby, 1997). The turbulence model selected is the $k-\varepsilon$ scheme (Rodi, 1984).

The model is forced by oscillating the water level on the northern edge with a tidal amplitude of $0.5 \mathrm{~m}$ and a period of $12 \mathrm{~h}$. Waves are also imposed on the northern edge with a height of $0.5 \mathrm{~m}$, directed to the south (zero angle), with a period of $2 \mathrm{~s}$. The test case setup is similar to the one used by Beudin et al. (2017). The test case setup is simulated for 2 days to obtain a tidally steady state solution. These simulations require $40 \mathrm{CPU}$ hours on Intel Xeon ${ }^{\circledR}$ X $56502.67 \mathrm{GHz}$ processors running on 24 parallel processors.
Table 2. Plant property input combinations for different simulations during sensitivity analysis.

\begin{tabular}{|c|c|c|c|c|}
\hline & $\begin{array}{r}\text { Stem density } \\
\left(\text { stems } \mathrm{m}^{-2}\right) \\
n_{v}\end{array}$ & $\begin{array}{r}\text { Height } \\
(\mathrm{m}) \\
l_{v}\end{array}$ & $\begin{array}{r}\text { Diameter } \\
(\mathrm{mm}) \\
b_{v}\end{array}$ & $\begin{array}{r}\text { Thickness } \\
(\mathrm{mm}) \\
t_{v}\end{array}$ \\
\hline 1. & 144.3 & 0.24 & 6.0 & 0.6 \\
\hline 2. & 62.1 & 0.17 & 3.0 & 0.6 \\
\hline 3. & 226.5 & 0.3 & 6.0 & 0.3 \\
\hline 4. & 144.3 & 0.17 & 9.0 & 0.9 \\
\hline 5. & 144.3 & 0.3 & 3.0 & 0.9 \\
\hline 6. & 62.1 & 0.3 & 6.0 & 0.3 \\
\hline 7. & 226.5 & 0.17 & 6.0 & 0.3 \\
\hline 8. & 144.3 & 0.3 & 9.0 & 0.9 \\
\hline 9. & 144.3 & 0.24 & 9.0 & 0.3 \\
\hline 10. & 226.5 & 0.24 & 6.0 & 0.9 \\
\hline 11. & 144.3 & 0.24 & 3.0 & 0.3 \\
\hline 12. & 62.1 & 0.24 & 6.0 & 0.9 \\
\hline 13. & 62.1 & 0.17 & 6.0 & 0.3 \\
\hline 14. & 62.1 & 0.24 & 9.0 & 0.6 \\
\hline 15. & 144.3 & 0.17 & 3.0 & 0.9 \\
\hline
\end{tabular}

\subsection{Choice of COAWST model response to vegetation inputs}

The output parameters used to investigate the vegetation model sensitivity are chosen to reflect the first-order effects of vegetation on the hydrodynamics and waves. The results for the model response are computed for the last tidal cycle (a total of three tidal cycles are required for achieving steady state). The presence of vegetation affects the output parameters in different physical ways (Table 1).

1. Wave energy dissipation: vegetation dissipates wave energy by reducing wave height, increasing wavelength, and reducing wave steepness.

2. Kinetic energy: a drag force is generated by plants. This leads to a decrease in kinetic energy within and behind the vegetation patch.

3. Water level: as the wave energy (and momentum) flux decreases due to bottom friction, the mean water level increases to balance the decrease in wave and kinetic energy. The flow decelerates in front of the patch and in the wake of the patch while it accelerates around the edges of the patch, leading to a water level gradient.

4. Turbulent kinetic energy (TKE): this refers to reduced turbulent kinetic energy in front and within the patch. The enhancement of TKE inside the boundary layer is not captured with the current resolution.

The response impact to change in the inputs during each simulation is computed by calculating the percentage difference of model response for each simulation from the minimum value of all the simulations. The model response is ob- 

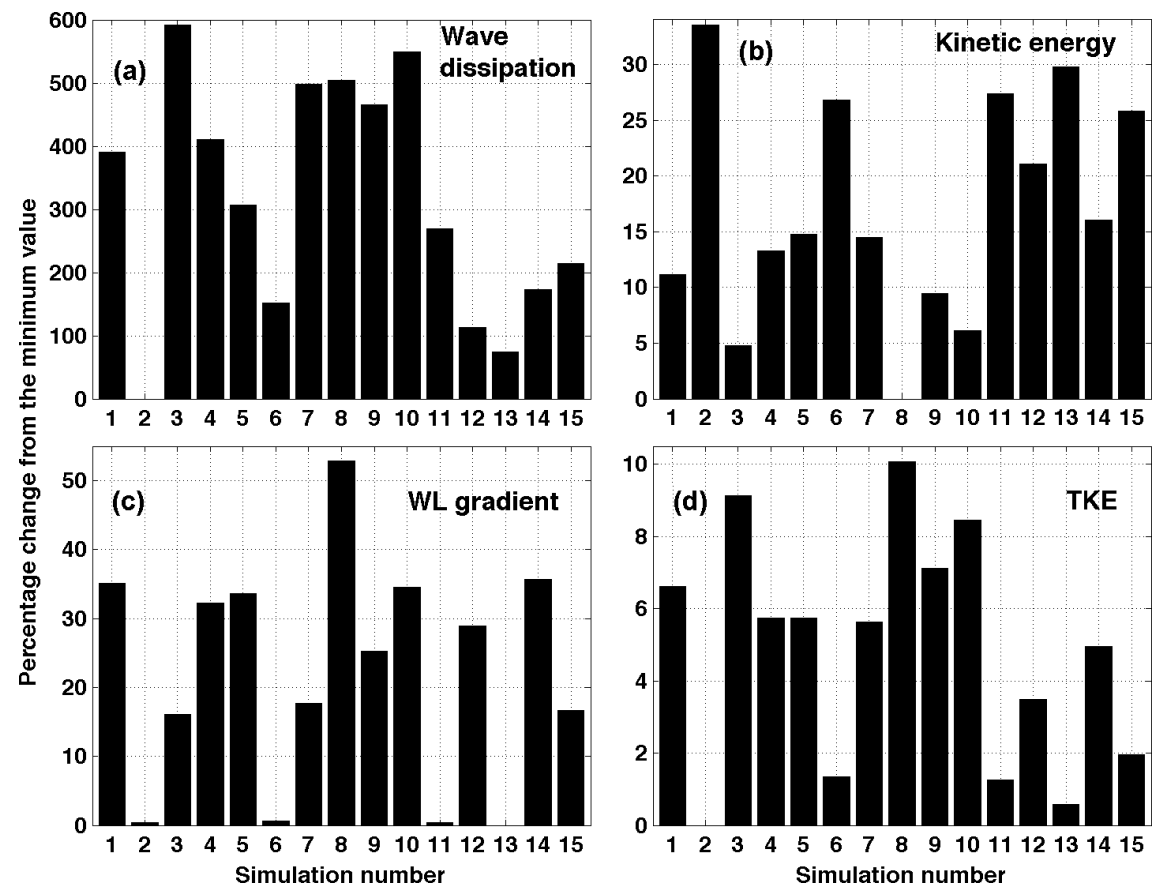

Figure 3. Percentage change from minimum for the four impact parameters: (a) wave dissipation; (b) kinetic energy; (c) maximum water level change (WL); and (d) turbulent kinetic energy (TKE).

tained in and around the vegetation patch and averaged over the last tidal cycle. The change in model response of water level is computed by finding the maximum water level difference in and around the vegetation patch. In addition, the variability of model response with given vegetation inputs in different simulations is calculated through standard deviation of model response in and around the vegetation patch over the last tidal cycle. The standard deviation in TKE is depth averaged to provide a 2-D field.

\section{Results}

\subsection{Setting up simulations with different vegetation inputs}

Using the range of input parameters described above (Sect. 2.3), and assuming all the inputs are uniformly distributed over their ranges, a matrix of design of experiment values (Table 2) was determined using Effective Quadratures. A total of 15 simulations were found to be required, corresponding to the number of coefficients in a 4-D polynomial with a maximum order of 2 . In general, the number of coefficients, $n$, is given by the formula

$n=\left(\frac{d+o}{d}\right)$,

where $d$ is the number of dimensions and $o$ is the maximum order (assuming it is isotropic across all dimensions).

\subsection{Model response from all the simulations}

The 15 simulations (parameter choice of each simulation in Table 2) are performed to provide model response from the four chosen output variables.

1. Wave dissipation: the percentage change in wave dissipation from all simulations relative to the minimum value of wave dissipation varied between 75 and $600 \%$ (Fig. 3a). Simulation 2, which includes the combination of smallest stem density $\left(n_{v}=62.1\right.$ stems $\left.^{-2}\right)$ and shortest height $(0.174 \mathrm{~m})$, incurred the least wave dissipation, while simulation 3, which involved the combination of greatest stem density $\left(n_{v}=226.5 \mathrm{stems} \mathrm{m}^{-2}\right)$ and tallest height $(0.295 \mathrm{~m})$, resulted in greatest wave dissipation. The greatest amount of variability in wave dissipation occurs in front of the vegetation patch (Fig. 4), where the greatest amount of wave energy is dissipated due to the presence of the vegetation patch.

2. Kinetic energy: the percentage change in kinetic energy from all simulations relative to the minimum kinetic energy varied between 5.0 and $34.0 \%$ (Fig. 3b). Simulation 8 , performed with an intermediate value of stem density along with the largest values of height, diameter, and thickness, results in the least amount of kinetic energy (lowest velocities). Simulation 2 causes the least amount of extraction of momentum with a combination of smallest plant stem density, height, and diameter values, resulting in the greatest kinetic energy in and 
around the vegetation patch. The variability in kinetic energy from all the simulations is observed at a cross section along the vegetation patch (Fig. 5). Variability is observed throughout the water column where the vegetation patch exists. Similar to the variability in wave dissipation, the greatest amount of variability occurs in front of the vegetation patch. The region of maximum variability occurs at a distance of $0.25-1.25 \mathrm{~m}$ above the bed.

3. Water level: the percentage change in maximum water level difference from all simulations relative to the minimum of the maximum water level difference varied between 3.0 and $18.0 \%$ (Fig. 3c). The minimum water level gradient is obtained from simulation 13 that includes a combination of plant inputs $\left(n_{v}=\right.$ $62.1 \mathrm{stems} \mathrm{m}^{-2}$ (minimum), $l_{v}=0.174 \mathrm{~m}$ (intermediate), diameter $=6 \mathrm{~mm}$ (minimum), and $t_{v}=0.3 \mathrm{~mm}$ (minimum). Simulations 2, 6, and 11 also give relatively low values of water level gradient. Simulations 2 and 6 both involve the smallest plant stem density values (i.e., $n_{v}=62.1 \mathrm{stems}^{-2}$ ). On the other hand, simulation $8\left(n_{v}=144.3\right.$ stems m$^{-2}, l_{v}=0.3 \mathrm{~m}$ (maximum), $b_{v}=9 \mathrm{~mm}$, and $t_{v}=0.9 \mathrm{~mm}$ ) accounts for the greatest value of maximum water level difference. The variability in water level (Fig. 6) is highest around the lobes of the vegetation patch where the water level adjusts due to changes in velocity around the patch. Behind the vegetation patch, the variability increases as the water level adjusts to the change in flow conditions.

4. Turbulent kinetic energy (TKE): the percentage change in TKE from all simulations relative to the minimum TKE varied between 0.5 and $10.0 \%$ (Fig. 3d). Simulation 8 (combination of plant $n_{v}=144.3 \mathrm{stems} \mathrm{m}^{-2}$, $l_{v}=0.3 \mathrm{~m}, b_{v}=9 \mathrm{~mm}$ and $\left.t_{v}=0.9 \mathrm{~mm}\right)$ gives the greatest amount of TKE, similar to what was observed with kinetic energy change. The smallest value of TKE is obtained in and around the vegetation patch in simulation 2 with a combination of plant inputs $\left(n_{v}=62.1 \mathrm{stems} \mathrm{m}^{-2}, l_{v}=0.2 \mathrm{~m}, b_{v}=3 \mathrm{~mm}\right.$, and $t_{v}=$ $0.6 \mathrm{~mm}$ ). Simulation 2 causes the least amount of dissipation of turbulence with a combination of smallest plant stem density, height and diameter. The variability in TKE peaks occurs in front of the vegetation patch (Fig. 7) where the different simulations dissipate turbulence to substantially different degrees. The changes in turbulence mixing caused by the presence of the vegetation patch are close to zero inside the patch (all simulations dissipate similar amounts of turbulence).

\subsection{Quantifying sensitivity using Sobol' indices}

Following the variability in model response from different simulations, the sensitivity to input vegetation parame-

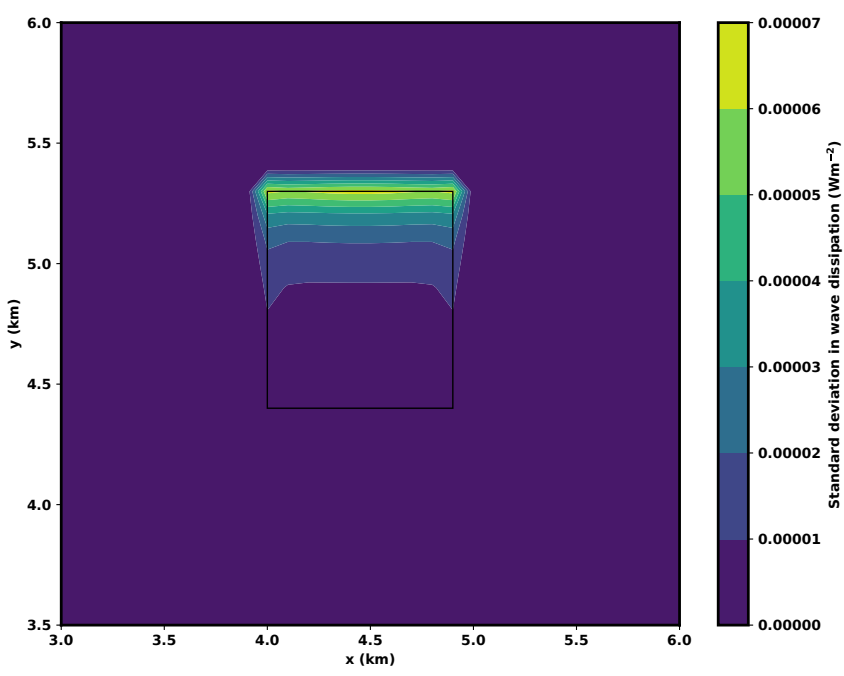

Figure 4. Standard deviation from wave dissipation $\left(\mathrm{W} \mathrm{m}^{-2}\right)$ in the presence of vegetation (plan view). The area of the vegetation patch is highlighted in the middle of the domain.

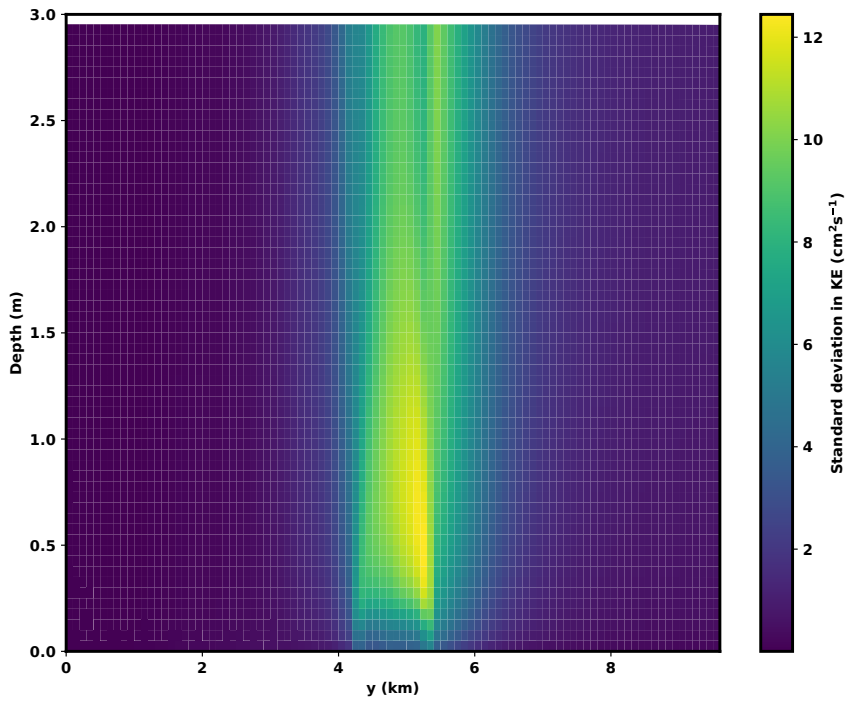

Figure 5. Standard deviation in kinetic energy $\left(\mathrm{cm}^{2} \mathrm{~s}^{-1}\right)$ in the presence of vegetation (cross-sectional view).

ters can be quantified with the use of first-order Sobol' indices that are obtained by taking advantage of the Effective Quadratures approach. Sobol' indices are individually computed for all the model responses. The first-order Sobol' indices for all the model responses (Table 3 ) add up to more than 0.9. This result indicates they account for $90 \%$ of the variability in model response for the given vegetation property inputs, and the variability captured by second-order and third-order indices is relatively low. The model is most sensitive (Table 3$)$ to plant stem density $\left(n_{v}\right)$ and height $\left(l_{v}\right)$ over the range of parameters considered; these two inputs account for over $80 \%$ of the sensitivity to all model outputs. The vegetation diameter $\left(b_{v}\right)$ accounts for $12-15 \%$ of model sensi- 


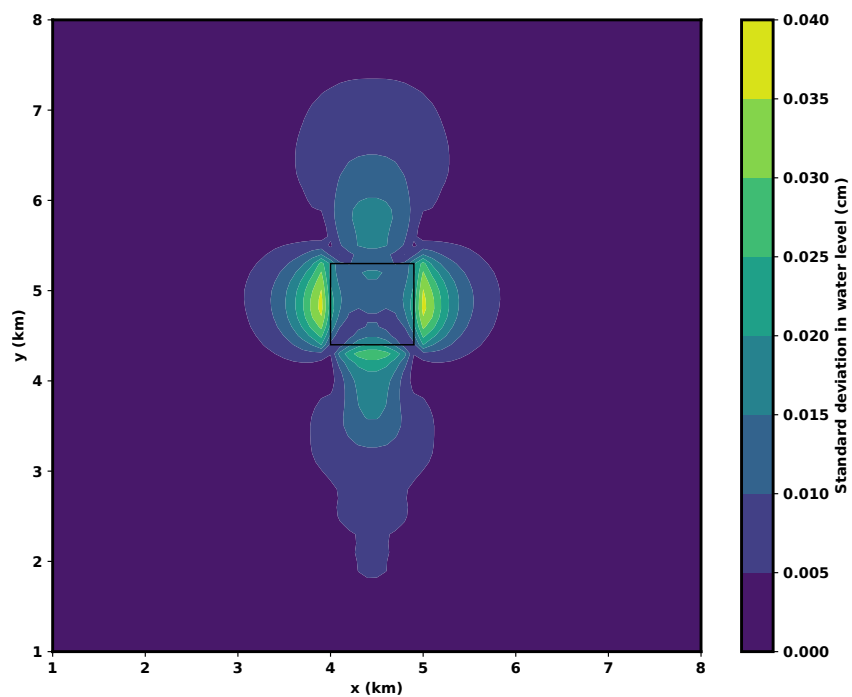

Figure 6. Standard deviation in water level in the presence of vegetation (plan view). The area of the vegetation patch is highlighted in the middle of the domain.

tivity to kinetic energy, water level change, and turbulent kinetic energy. Thickness $\left(t_{v}\right)$ showed the least impact on all the chosen model outputs.

\section{Discussion}

\subsection{Variability in model response from sensitivity analysis}

From the different simulations performed during sensitivity analysis, there is a great amount of variability in front of the vegetation patch in wave dissipation, kinetic energy (KE), and TKE (Figs. 4, 5, and 7). This is a result of large amount of wave dissipation and flow deceleration in front of the vegetation patch. The cross-sectional plane of the domain illustrates that the variability in KE occurs throughout the water column (Fig. 5), highlighting the 3-D impact of vegetation inputs. Interestingly, the greatest amount of variability in KE (Fig. 5) occurs at distance above the bed between 0.4 and $1.3 \mathrm{~m}$ at $y=5.6 \mathrm{~km}$, while the maximum vegetation height in all the simulations is $0.3 \mathrm{~m}$. This result indicates that variation in vegetation height results in the greatest amount of KE variability above the vegetation patch. The variability in water level change is large around the lobes and behind the vegetation patch (Fig. 6). The variability in these regions is because the change in local flow velocity is adjusted by a change in water level around the vegetation patch. This is further confirmed by observing the variation in velocity profiles with depth (Fig. 8a) at a particular time instance during flood tide. Simulation 8 results in the lowest velocity of $0.06 \mathrm{~m} \mathrm{~s}^{-1}$, while simulation 2 results in the peak flood velocity of $0.11 \mathrm{~m} \mathrm{~s}^{-1}$. Consequently, the gradient of velocity

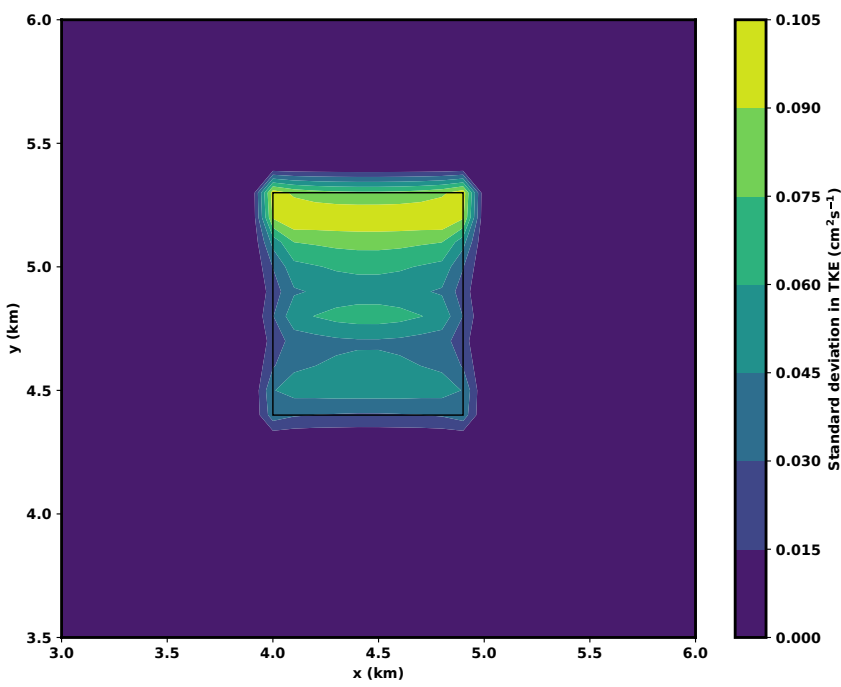

Figure 7. Standard deviation in TKE $\left(\mathrm{cm}^{2} \mathrm{~s}^{-1}\right)$ in the presence of vegetation (plan view). The area of the vegetation patch is highlighted in the middle of the domain.

Table 3. Sobol' indices for all the outputs.

\begin{tabular}{lrrrr}
\hline & $\begin{array}{r}\text { Plant stem } \\
\text { density } \\
n_{v}\end{array}$ & $\begin{array}{r}\text { Plant } \\
\text { height } \\
l_{v}\end{array}$ & $\begin{array}{r}\text { Plant } \\
\text { diameter } \\
b_{v}\end{array}$ & $\begin{array}{r}\text { Plant } \\
\text { thickness } \\
t_{v}\end{array}$ \\
\hline Wave dissipation & 0.68 & 0.24 & 0.032 & 0.01 \\
Kinetic energy & 0.36 & 0.44 & 0.12 & 0.03 \\
Maximum water level change & 0.38 & 0.43 & 0.15 & 0.01 \\
Turbulent kinetic energy & 0.35 & 0.42 & 0.12 & 0.03 \\
\hline
\end{tabular}

with respect to depth is greatest at all depths for simulation 8 , while it is lowest for simulation 2 (Fig. 8b). The gradient reaches a maximum value at the bottom layer.

\subsection{Understanding vegetation parameterization to interpret Sobol' indices}

The parameterizations involving extraction of momentum, turbulence production, and turbulence dissipation are directly affected by vegetation stem density $\left(n_{v}\right)$, diameter $\left(b_{v}\right)$, and thickness $\left(t_{v}\right)$ (Table 1). Because these mechanistic processes occur at the blade scale, the dependence on vegetation height $\left(l_{v}\right)$ is implicitly included in the parameterizations. Sobol' indices provide quantifiable information and show that vegetation height, stem density, and diameter (in decreasing order of importance) are pertinent in accurately computing KE, TKE, and water level. An accurate representation of KE and TKE has direct ramifications on estimating sediment transport while water level estimates can affect storm surge predictions.

The high sensitivity of wave dissipation to vegetation stem density highlights the need for accurate density representation to attain wave attenuation estimates, especially in open coasts. SWAN computes wave dissipation due to vegetation 


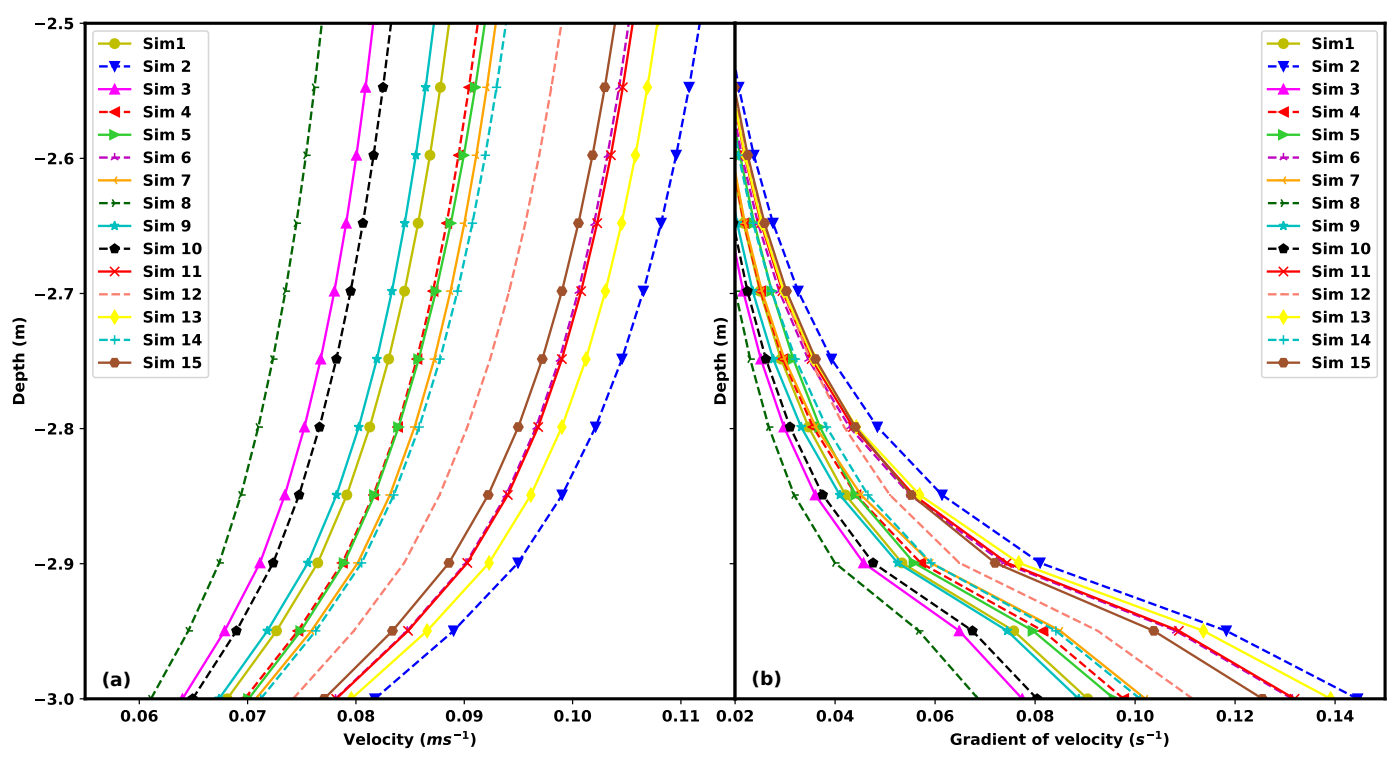

Figure 8. (a) Velocity $\left(\mathrm{m} \mathrm{s}^{-1}\right)$ profile and (b) vertical gradient $\left(\mathrm{s}^{-1}\right)$ of velocity profile varying with depth in front of the vegetation patch at a particular time instance during flood for different simulations.

as a bottom layer effect. Therefore, the height of the vegetation does not affect wave dissipation to the same extent as other model outputs: KE, TKE, and water level. In addition, the equation representing the wave dissipation process in SWAN is independent of vegetation thickness, thus corresponding to the lowest Sobol' index. Vegetation thickness only appears in the turbulence dissipation term (Table 1); modifying the turbulence length scale has the least effect on any of the model responses.

\subsection{Linear curve fitting to complement Effective Quadratures based sensitivity analysis}

To complement the results of the Sobol' indices' calculation, linear fits to the data are conducted. The main parameter contributing to the wave dissipation variability is the stem density, explaining over $80 \%$ of the variability $\left(R^{2}=0.81\right)$. The least squared fit to wave dissipation that included all parameters combined explains $98 \%$ of the variability. When fitting models, it is possible to increase the explained variance by using more complex fitting models adding parameters, but doing so may result in overfitting. The Bayesian information criterion (BIC; Schwarz, 1978; Aretxabaleta and Smith, 2011) provides a non-subjective metric for the best fit by penalizing overparameterization. BIC resolves overfitting by introducing a penalty term for the number of parameters in the model. For wave dissipation, the BIC approach identified a fit based exclusively on density as the model that best matches the data while preventing overfitting. The selection of density as the single most relevant parameter is consistent with the Sobol' indices' result (Table 3).

The kinetic energy variability is also associated with stem density changes, but the percentage of explained variability
(42\%) is smaller than for wave dissipation. Diameter and height also contributed to changes in kinetic energy. The combination of stem density, height, and diameter provided the optimal fit of the data (selected by minimizing BIC) and explained $89 \%$ of variability in kinetic energy. Similar results were obtained for TKE, with density explaining $45 \%$ of the variability but the combination of stem density, height, and diameter providing the optimal fit to TKE (selected by minimizing BIC) and explained $87 \%$ of the variability. The model response of water level variability is also best explained by a combination of stem density, height, and diameter ( $96 \%$ of water level variance explained). Thickness was not correlated with wave dissipation, kinetic energy, or TKE and only contributed to water level gradient variability.

\subsection{Limitations of the current sensitivity methodology}

The model configuration chosen includes vegetation covering a small fraction of the water column to allow for proper wave dissipation. Many species of seagrass have a larger vertical footprint and can also exhibit much higher shoot densities. The goal of the study is to provide estimates on the relative importance of the different parameters through a robust sensitivity approach. The current work assumed rigid vegetation blades, while the model is capable of including flexible vegetation by altering the blade scale. The expected effect of flexible blades would be to reduce the relative importance of vegetation length $\left(l_{v}\right)$ on the model outputs. In addition, the present work assumes a constant drag coefficient for cylindrical vegetation shape; the influence of a variability drag coefficient can be a subject of a future sensitivity study. Other model parameters such as vertical and horizontal resolution, mixing parameterization, and wave and hydrodynamic forc- 
ings will also affect model results but were beyond the scope of the current study.

\section{Conclusions}

The coupled wave-flow-vegetation module in the COAWST modeling system provides a tool to study vegetated flows in riverine, lacustrine, estuarine, and coastal environments. The resulting flow field in the presence of vegetation depends on its properties, including vegetation stem density, height, diameter, and thickness. The sensitivity of the hydrodynamic and wave conditions to changes in vegetation parameters is investigated. The sensitivity analysis helps in understanding the multi-parameter/multi-response of various interactions within the model. We use an existing tool that formulates the Effective Quadratures method to quantify the sensitivity of plant input properties for the vegetation module in COAWST model. The decomposition of the variance of the model solution given by the Sobol' indices is assigned to plant parameters.

The method of using Sobol' indices to quantify sensitivity can be computationally expensive. One of the goals of this work is to demonstrate a robust, practical, and efficient approach for the parameter sensitivity analysis. We show that the approach of using the Effective Quadratures method to select a parameter space that is consistent with physical understanding significantly reduces the computational time required to obtain the Sobol' indices.

The evaluation of Sobol' indices shows that the input values of plant stem density, height, and, to a lesser degree, diameter are consequential in determining kinetic energy, turbulent kinetic energy, and water level changes. Meanwhile, the wave dissipation is mostly dependent on the variation in plant density.

The sensitivity analysis for the vegetation model in COAWST presented herein provides guidance for observational and modeling work by allowing future efforts to focus on constraining the most influential inputs without having to explore the entire parameter space. An accurate representation of processes causing kinetic energy and turbulent kinetic energy leads to enhanced understanding of sediment processes while accurate water level computations help to predict coastal flooding caused by storm surge. Similarly, wave attenuation measurements in open coasts are better understood with a correct representation of wave dissipation. In the future, we intend to perform a similar sensitivity analysis with the inclusion of a biological model that will affect plant growth, thus allowing a time dependence of model input and response. In addition, the influence of vegetation on sediment transport will be explored. As model complexity increases with more parameters representing additional processes, input parameter sensitivity is required for the model to be applied in practical applications.
Code availability. The Effective Quadratures methodology is an open-source Python-based tool designed to perform sensitivity analysis for a given physical system. The instructions to install the code along with all the open-source files for this tool are detailed here: https://github.com/Effective-Quadratures/ Effective-Quadratures (Seshradi, 2017; Seshadri and Parks, 2017). For any further inquiries about the Effective Quadratures methodology, please contact the corresponding author, Pranay Seshadri (ps583@cam.ac.uk).

The COAWST model is an open-source coupled hydrodynamics and wave model containing vegetation effects mainly coded in Fortran 77. This model provided the physical setting to perform the sensitivity analysis. The code is available from https://coawstmodel-trac.sourcerepo.com/coawstmodel_ COAWST (Warner, 2017; Warner et al., 2010) after registration via email with J. C. Warner (jcwarner@usgs.gov).

Data availability. The model output from various simulations used to perform sensitivity analysis in this study is available at http://geoport.whoi.edu/thredds/catalog/clay/usgs/users/tkalra/ senstivity_study/catalog.html (USGS/WHCMSC, 2017). The link contains a "README.txt" file that explains how the folder is organized to contain model output.

Author contributions. TSK and NKG designed and simulated the numerical experiment space for sensitivity analysis. PS developed the Effective Quadratures methodology to quantify the model sensitivity. AB provided inputs on the mechanistic processes involving the vegetation model. TSK and AA performed the data analysis from the output of sensitivity study and prepared the paper with contributions from all co-authors.

Competing interests. The authors declare that they have no conflict of interest.

Disclaimer. Any use of trade, firm, or product names is for descriptive purposes only and does not imply endorsement by the US Government.

Acknowledgements. We thank Jeremy Testa at the University of Maryland Center for Environmental Science for providing us guidance on the ranges of vegetation for sensitivity studies in the early stages of work. We also thank P. Soupy Daylander at the US Geological Survey, St. Petersburg Coastal and Marine Science Center, for providing her feedback to improve the clarity of the paper. We thank the anonymous reviewers for their careful reading of our manuscript and their insightful comments and suggestions.

Edited by: Paul Halloran

Reviewed by: two anonymous referees 


\section{References}

Aretxabaleta, A. L. and Smith, K. W.: Analyzing state-dependent model-data comparison in multi-regime systems, Computat. Geosci., 15, 627-636, 2011.

Bacchi, V., Gagnaire, E., Durand, N., and Benoit, M.: Wave energy dissipation in TOMAWAC, Telemac \& Mascaret User Club, 1517 October 2014, Grenoble, France, 2014.

Bastidas, L. A., Gupta, H. V., Sorooshian, S., Shuttleworth, W. J., and Yang, Z. L.: Sensitivity analysis of land surface scheme using multicriteria methods, J. Geophys. Res., 104, 481-490, 1999.

Beudin, A., Kalra, T. S., Ganju, N. K., and Warner, J. C.: Development of a Coupled Wave-Current-Vegetation Interaction, Comput. Geosci., 100, 76-86, 2017.

Booij, N., Ris, R. C., and Holthuijsen, L. H.: A third-generation wave model for coastal regions: 1 . Model description and validation, J. Geophys. Res.-Oceans, 104, 7649-7666, 1999.

Bryan, F.: Parameter Sensitivity of Primitive Equation Ocean General circulation models, J. Phys. Oceanogr., 17, 970-985, https://doi.org/10.1175/15200485(1987)017<0970:PSOPEO>2.0.CO;2, 1987.

Carr, J., D’Odorico P., McGlathery K., and Wiberg, P.: Stability and bistability of seagrass ecosystems in shallow coastal lagoons: role of feedbacks with sediment resuspension and light attenuation, J. Geophys. Res.-Biogeo., 115, G03011, 2010.

Chen, S. N., Sanford L., Koch, E. W., Shi F., and North, E. W.: A nearshore model to investigate the effects of seagrass bed geometry on wave attenuation and suspended sediment transport, Estuar. Coast., 30, 296-310, 2007.

Costanza, R., d'Arge, R., de Groot, R., Farberk, S., Grasso, M., Hannon, B., Limburg, K., Naeem, S., O’Neill, R. V., Paruelo, J., and Raskin, R. G.: The value of the world's ecosystem services and natural capital, Nature, 387, 253-260, 1997.

Dalrymple, R. A., Kirby, J. T., and Hwang, P. A.: Wave diffraction due to areas of energy dissipation, J. Waterw. Port C., 110, 6779, 1984.

de Vriend, H. J.: Integrated Research Results on Hydrobiosedimentary Processes in Estuaries, Final Report of the Estuary Process Research Project (EstProc): Algorithms and Scientific Information, R\&D Technical Report FD1905/TR3, Defra - Flood Management Division Ergon House, London, UK, 2006.

Fennel, K., Losch, M., Schroter, J., and Wenzel, M.: Testing a marine ecosystem model: sensitivity analysis and parameter optimization, J. Marine Syst., 28, 45-63, https://doi.org/10.1016/S0924-7963(00)00083-X, 2001.

Ganju, N. K., Sherwood, C. R.: Effect of roughness formulation on the performance of a coupled wave, hydrodynamic, and sediment transport model, Ocean Model., 33, 299-313, 2010.

Geraci, G., Congedo, P. M., Abgrall, R., and Iaccarino, G.: Highorder statistics in global sensitivity analysis: Decomposition and model reduction. Comput. Method. Appl. M., 301, 80-115, 2016

Haidvogel, D. B., Arango, H. G., Budgell, W. P., Cornuelle, B. D., Curchitser, E., Di Lorenzo, E., Fennel, K., Geyer, W. R., Hermann, A. J., Lanerolle, L., Levin, J., McWilliams, J. C., Miller, A. J.,. Moore, A. M, Powell, T. M., Shchepetkin, A. F., Sherwood, C. R., Signell, R. P., Warner, J. C., and Wilkin, J.: Ocean forecasting in terrain-following coordinates: formulation and assessment of the regional ocean modeling system, J. Comput. Phys., 227, 3595-3624, 2008.
Heck, K. L., Hays, G., and Orth, R. J.: Critical evaluation of the nursery role hypothesis for seagrass meadows, Mar. Ecol. Prog. Ser., 253, 123-136, 2003.

Kennish, M. J., Fertig, M. B., and Sakowicz, G. P.: In situ Surveys of Seagrass Habitat in the Northern Segment of the Barnegat BayLittle Egg Harbor Estuary, Barnegat Bay Partnership, Final Report, Toms River, NJ, USA, 2013.

Kombiadou, K., Ganthy, F., Verney, R., Plus, M., and Sottolichio, A.: Modelling the effects of Zostera noltei meadows on sediment dynamics: application to the Arcachon lagoon, Ocean Dynam., 64, 1499-1516, 2014.

Lapetina, A. and Sheng, Y. P.: Three-dimensional modeling of storm surge and inundation including the effects of coastal vegetation, Estuar. Coast., 37, 1028-1040, 2014.

Larkum, A. W. D., Orth, R. J., and Duarte, C. M. (Eds.): Seagrasses: Biology, Ecology and Conservation, Springer Netherlands, 2007.

Le Bouteiller, C. and Venditti, J. G.: Sediment transport and shear stress partitioning in a vegetated flow, Water Resour. Res., 51, 2901-2922, https://doi.org/10.1002/2014WR015825, 2015.

Luhar, M., Coutu, S., Infantes, E., Fox, S., and Nepf, H. M.: Waveinduced velocities inside a model seagrass bed, J. Geophys. Res.Oceans, 115, C12005, 2010.

Madsen, O. S.: Spectral wave-current bottom boundary layer flows, Proceedings of the 24th International Conference on Coastal Engineering Research Council, Kobe, Japan, 384-398, 1994.

Mendez, F. M. and Losada, I. J.: An empirical model to estimate the propagation of random breaking and nonbreaking waves over vegetation fields, Coast. Eng., 51, 103-118, 2004.

Möller, I., Spencer, T., French, J. R., Legget, D. J., and Dixon, M.: Wave transformation over salt marshes: a field and numerical modeling study from Norfolk, England. Estuarine, Coastal and Shelf Science, 49, 411-426, 1999.

Morin, J., Leclerc, M., Secretan, Y., and Boudreau, P.: Integrated two-dimensional macrophytes-hydrodynamic modelling, J. Hydraul. Res., 38, 163-172, 2000.

Mourre, B., Ballabrera-Poy, J., García-Ladona, E., Font, J.: Surface salinity response to changes in the model parameters and forcings in a climatological simulation of the eastern North-Atlantic Ocean, Ocean Model., 23, 37-49, 2008.

Ree, W. O.: Hydraulic characteristics of vegetation for vegetated waterways, Agr. Eng., 30, 184-189, 1949.

Rodi, W.: Turbulence models and their application in hydraulics, a state of the art review, Technical report, International Association of Hydraulics Research, Delft, 1984.

Rosero, E., Yang, Z. L., Wagener, T., Gulden, L. E., Yatheendradas, S., and Niu, G. Y.: Quantifying parameter sensitivity, interaction, and transferability in hydrologically enhanced versions of the Noah land surface model over transition zones during the warm season, J. Geophys. Res., 115, D03106, https://doi.org/10.1029/2009JD012035, 2010.

Saltelli, A., Ratto, M., Andres, T., Campolongo, F., Cariboni, J., Gatelli, D., Saisana, M., and Tarantola, S.: Global sensitivity analysis: the primer, John Wiley \& Sons, Chichester, 312 pp., 2008.

Schwarz, G.: Estimating the dimension of a model, Ann. Stat., 6, 461-464, 1978.

Seshadri, P.: Effective-Quadratures/Effective-Quadratures: Suite of tools for polynomial approximations, GitHub, available at: https: 
//github.com/Effective-Quadratures/Effective-Quadratures, last access: 20 November 2017.

Seshadri, P. and Parks, G. T.: Effective Quadratures (EQ): Polynomials for Computational Engineering Studies, Journal of Open Source Software, 2, https://doi.org/10.21105/joss.00166, 2017.

Seshadri, P., Narayan, A., and Mahadevan, S.: Effectively Subsampled Quadratures for Least Squares Polynomial Approximations, SIAM/ASA, Journal of Uncertainty Quantification, 5, 1003-1023, https://doi.org/10.1137/16M1057668, 2017.

Smith, R. C.: Uncertainty quantification: theory, implementation, and applications, SIAM, Computational Science and Engineering Series, CS12, 2014.

Sobol', I. M.: Sensitivity estimates for nonlinear mathematical models, Mathematical Modelling and Computational Experiments, 1.4, 407-414, 1993.

Soulsby, R. L.: Dynamics of Marine Sands, Thomas Telford, London, 249 pp., 1997.

Sudret, B.: Global sensitivity analyzing using polynomial chaos expansions, Reliability Engineering and System Safety, 93, 964 979, 2008

Suzuki, T., Zijlema, M., Burger, B., Meijer, M. C., and Narayan, S.: Wave dissipation by vegetation with layer schematization in SWAN, Coast. Eng., 59, 64-71, 2012.

Temmerman, S., Bouma, T. J., Govers, G., Wang, Z. B., De Vries, M. B., and Herman, P. M. J.: Impact of vegetation on flow routing and sedimentation patterns: three-dimensional modeling for a tidal marsh, J. Geophys. Res.-Earth, 110, F04019, https://doi.org/10.1029/2005JF000301, 2005.

Uittenbogaard, R.: Modelling turbulence in vegetated aquatic flows, International workshop on Riparian Forest vegetated channels: hydraulic, morphological and ecological aspects, Trento, Italy, 2003.
USGS/WHCMSC: Model output of sensitivity analysis for the COAWST vegetation model, United States Geological Survey, Woods Hole Coastal and Marine Science Center (WHCMSC) Sediment Transport Group, MA, USA, available at: http://geoport.whoi.edu/thredds/catalog/clay/usgs/users/ tkalra/senstivity_study/catalog.html, last access: 1 December 2017.

Wamsley, T. V., Cialone, M. A., Smith, J. M., Atkinson, J. H. and Rosati, J. D.: The potential of wetlands in reducing storm surge, Ocean Eng., 37, 59-68, 2010.

Warner, J. C.: COAWST: Coupled-Ocean-Atmosphere-WaveSediment Transport Model, United States Geological Survey (USGS), Woods Hole Coastal and Marine Science Center (WHCMSC), Sediment Transport Group, MA, USA, available at: https://coawstmodel-trac.sourcerepo.com/coawstmodel_ COAWST, last access: 1 December 2017.

Warner, J. C., Perlin, N., and Skyllingstad, E. D.: Using the Model Coupling Toolkit to couple earth system models, Environ. Modell. Softw., 23, 1240-1249, 2008a.

Warner J. C., Sherwood, C. R., Signell, R. P., Harris, C. K., and Arango, H.G.: Development of a three-dimensional, regional, coupled wave, current, and sediment-transport model, Comput. Geosci., 34, 1284-1306, 2008b.

Warner, J. C., Armstrong, B., He, R., and Zambon, J. B.: Development of a Coupled Ocean-Atmosphere-Wave-Sediment Transport (COAWST) Modeling System, Ocean Model., 35, 230-244, https://doi.org/10.1016/j.ocemod.2010.07.010, 2010.

Wu, W.: A 3-D phase-averaged model for shallow-water flow with waves in vegetated water, Ocean Dynam., 64, 1061-1071, 2014.

Xiu, D. and Karniadakis, G. E.: The Wiener-Askey polynomial chaos for stochastic differential equations, SIAM J. Sci. Comput., 24, 614-644, 2002. 